\title{
Lidar-based remote sensing of atmospheric boundary layer height over land and ocean
}

\author{
T. Luo ${ }^{1,2}$, R. Yuan ${ }^{2}$, and Z. Wang ${ }^{1}$ \\ ${ }^{1}$ University of Wyoming, Dept. Atmospheric Science, Laramie, WY, USA \\ ${ }^{2}$ University of Science and Technology of China, School of earth and space science, Hefei, Anhui, China \\ Correspondence to: T. Luo (tluo@uwyo.edu)
}

Received: 17 July 2013 - Published in Atmos. Meas. Tech. Discuss.: 9 September 2013

Revised: 29 November 2013 - Accepted: 4 December 2013 - Published: 22 January 2014

\begin{abstract}
Atmospheric boundary layer (ABL) processes are important in climate, weather and air quality. A better understanding of the structure and the behavior of the ABL is required for understanding and modeling of the chemistry and dynamics of the atmosphere on all scales. Based on the systematic variations of the ABL structures over different surfaces, different lidar-based methods were developed and evaluated to determine the boundary layer height and mixing layer height over land and ocean. With Atmospheric Radiation Measurement Program (ARM) Climate Research Facility (ACRF) micropulse lidar (MPL) and radiosonde measurements, diurnal and season cycles of atmospheric boundary layer depth and the ABL vertical structure over ocean and land are analyzed. The new methods are then applied to satellite lidar measurements. The aerosol-derived global marine boundary layer heights are evaluated with marine $\mathrm{ABL}$ stratiform cloud top heights and results show a good agreement between them.
\end{abstract}

\section{Introduction}

The atmospheric boundary layer (ABL) is the turbulent layer near the Earth's surface (Stull, 1988). The heat, moisture and aerosols are trapped and vertically mixed within the $\mathrm{ABL}$, and are exchanged with the free troposphere at the top of the ABL. Therefore, boundary layer height (BLH) acts as a key length scale in weather, climate, and air quality models to determine turbulence mixing, vertical diffusion, convective transport and cloud formation (Garratt, 1992; Seibert et al., 2000; Stevens, 2002; Erickson et al., 2008; Kukkonen et al., 2012; Zilitinkevich, 2012; Ferrare et al.,
2013). However, in operational forecast models, regional models, or global climate models, the ABL is still poorly simulated due to complex processes at small temporal and spatial scales (Lenderink and Holtslag, 2000; Hannay et al., 2009; Wyant et al., 2010). The modeled ABL is also not fully evaluated due to the lack of a reliable global BLH climatology database (Seidel et al., 2010). Therefore, a better understanding of the ABL structure and physical processes is required to improve model simulations.

Despite its importance, the BLH is difficult to be directly measured by standard meteorological measurements (Tombrou et al., 2007; Liu and Liang, 2010). The ABL is generally described as the lowest layer of atmosphere that is directly influenced by the Earth's surface, and responds to changes in the surface within a short amount of time (Stull, 1988). Usually, the BLH is indirectly diagnosed from an analysis of thermodynamic variables, turbulence-related parameters or measuring concentrations of tracers, by using different definitions of the BLH with respect to the various characteristics of the ABL, as reviewed by Seidel et al. (2010). However, different definitions often give different BLH results, and no standard BLH definition exists (Seidel et al., 2010). Seidel et al. (2010) recommended either the parcel method or the Richardson number (RI) method to be the most reliable method. The RI method is applied to radiosonde data in this study, as detailed in Sect. 2.2.

Satellite-based observations allow a non-traditional way of deriving the global BLH climatology. A few studies have been done by using Global Positioning System radio occultation (GPS RO) measurements (Ratnam and Basha, 2010; Guo et al., 2011; Ao et al., 2012) or Cloud-Aerosol Lidar and Infrared Pathfinder Satellite Observation (CALIPSO) 
(McGrath-Spangler and Denning, 2013). GPS RO provides a valuable global view of the height-resolved refractivity or moisture structure of ABL. However, GPS RO has very coarse resolutions $(200 \mathrm{~m}$ in vertical and $\sim 200 \mathrm{~km}$ horizontal), and suffers several problems such as insufficient penetration into the lowest $500 \mathrm{~m}$ of the atmosphere (Xie et al., 2012). CALIPSO has much finer vertical $(30 \mathrm{~m})$ and horizontal resolution $(333 \mathrm{~m})$ and is sensitive to boundary layer aerosols and clouds. Former studies showed that CALIPSO has the great ability to derive global BLH distributions (Jordan et al., 2010; McGrath-Spangler and Denning, 2012, 2013). However, the variance methods used in these studies often gave lower BLH than the other methods (as will be shown in Sect. 2.3), and the previous work mainly relies on in situ measurements to evaluate the global BLH climatology (i.e., McGrath-Spangler and Denning, 2013). The in situ measurements are sparse and mainly over land, thus the limited evaluation results may not be so representative for global BLH distribution.

CALIPSO could be a more powerful tool to provide the global BLH data sets. However, careful further evaluations are needed. Usually the ABL has more content of aerosol than free upper atmosphere due to the limitation of capping inversion at the top of the ABL and primary near-surface aerosol sources. Near-surface aerosols are mixed within ABL by turbulence and convection, thus aerosol vertical distribution is heavily influenced by the thermal structure. Aerosol vertical structure is regarded as a good tracer to determine the BLH (Stull and Eloranta, 1984; Boers et al., 1984; Melfi et al., 1985; Boers and Eloranta, 1986). Lidar provides direct measurements of aerosol profiles within the ABL. Several methods, such as the threshold method, gradient method, and variance method, have been developed to determine BLH by using lidar backscatter measurements (Hooper and Eloranta, 1986; Flamant et al., 1997; Menut et al., 1999; Sicard et al., 2006; Lammert and Bösenberg, 2006; Martucci et al., 2007; Emeis et al., 2008; Jordan et al., 2010; Haeffelin et al., 2012). However, the detected aerosol layers are not always consistent with ABL thermodynamical structures because aerosol vertical structures are affected by other factors. First, local aerosol vertical distributions are influenced by horizontal transportation of aerosols besides vertical turbulence mixing. Second, the nighttime aerosol residual layer has weak linkages with $\mathrm{ABL}$ processes and it is hard to distinguish the ABL aerosol (Martucci et al., 2007; Baars et al., 2008; Ferrare et al., 2013), especially over land. Therefore, a careful evaluation of lidar-based BLH is needed in order to provide consistent BLH based on thermodynamical properties under different surface and thermal conditions.

This study aims to improve lidar-based method to provide consistent BLH determinations as other methods based on thermodynamical properties (the RI method). Long-term collocated lidar and radiosonde data is used to evaluate lidarbased BLH determination methods over land and ocean. The method is applied to space-borne lidar measurements to derive a global marine ABL structure database. Due to limited ground-base observations to evaluate this large global ocean data set, marine BLH are evaluated with lidarmeasured boundary layer stratiform cloud top heights, which is capped by the boundary layer top temperature inversion. Section 2 describes the ground- and satellite-based data and BLH identification methodology. Section 3 gives the results and some discussions, and Sect. 4 presents a brief conclusion.

\section{Methodology}

\subsection{Data}

\subsubsection{Ground-based data}

Atmospheric Radiation Measurement Program (ARM) Climate Research Facility (ACRF) radiosonde and micro pulse lidar (MPL) observations (Xie et al., 2010; Mather and Voyles, 2013) were used to investigate the boundary layer aerosol structure and to develop new lidar-based methods to determine the BLH over different surfaces. The Nauru (marine site, 2007-2008) and Southern Great Plains (continental site, 2007-2009) sites were selected to represent typical ocean and land conditions. The Nauru site $\left(0^{\circ} 31^{\prime} 15.6^{\prime \prime} \mathrm{S}, 166^{\circ} 54^{\prime} 57.60^{\prime \prime} \mathrm{E}\right)$ is located on a small island in the western South Pacific. The Southern Great Plains site $\left(36^{\circ} 36^{\prime} 18.0^{\prime \prime} \mathrm{N}, 97^{\circ} 29^{\prime} 6.0^{\prime \prime} \mathrm{W}\right)$ is located on the SGP Central Facility, Lamont, OK, US. These two sites have long-term radiosonde and lidar measurements, which allows us to develop the lidar-based method and evaluate it with radiosonde observations.

1. Balloon-borne sounding system (SONDE) provides in situ measurements (vertical profiles) of temperature, water vapor and the wind speed and direction, at a frequency of 2 times per day at the marine site and 4 times per day at the continental site.

2. The MPL ( $532 \mathrm{~nm}$ wavelength) has $30 \mathrm{~m}$ (or $15 \mathrm{~m}$ ) vertical resolution and $18 \mathrm{~km}$ maximum height range, and the typical averaging of MPL data is $10 \mathrm{~s}$ (Coulter, 2012). Because only cloud-free ABL shall be studied, clouds need to be screened out of the long-term MPL set. This is done the following way. After overlap correction, the cloud is detected with the slope algorithm based on Wang and Sassen (2001), which uses the change in the slope of the backscattered signal as a function of height to identify the presence of cloud layers in the atmosphere, and uses several techniques to distinguish aerosol layers from cloud layers. Then, cloud-free signals (no cloud below $7 \mathrm{~km}$ ) were averaged into a $1 \mathrm{~h}$ resolution. Usually the aerosol layer is lower than $5 \mathrm{~km}$, thus signals within $5 \mathrm{~km}$ and $6 \mathrm{~km}$ are selected to calibrate the observed total attenuated 

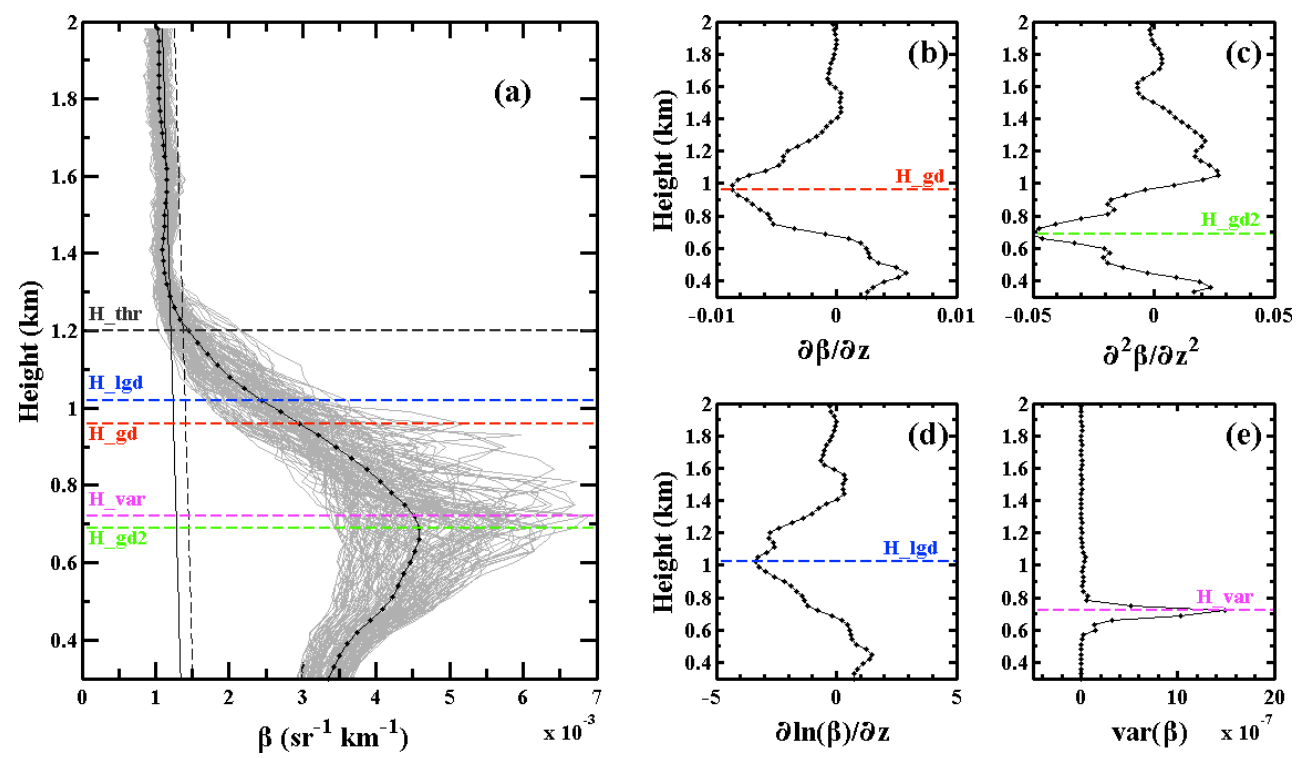

Fig. 1. Comparison of BLH determinations from lidar measurements with five different methods. $\beta$ denotes the lidar backscatter intensity $\left(\mathrm{sr}^{-1} \mathrm{~km}^{-1}\right)$. (a) Comparing of BLH derived from different methods. The gray lines are the measured 30 s-averaged $\beta$ within $1 \mathrm{~h}$ centered at 04:30 LT, 24 June 2007 at the continental site. The black dotted line is the averaged $\beta$ of all gray lines. $H \_$thr denotes the BLH derived by the threshold method; $H \_$gd denotes the BLH derived by the gradient or derivation method (b); $H \_g d 2$ denotes the BLH derived by the second derivation method (c); $H_{-} \operatorname{lgd}$ denotes the BLH derived by the log-gradient method (d); $H_{-}$var denotes the BLH derived by the variance (var) method (e) using the data shown as the gray lines in (a).

backscattering (TAB) profile with molecular backscattering coefficients, which are estimated with SONDE temperature and pressure profiles. Due to uncertainties in overlap correction below $500 \mathrm{~m}$, MPL TABs below $500 \mathrm{~m}$ are not used in this study.

\subsubsection{Satellite-base data}

To build a global marine BLH database, multiple remotely sensed and operational meteorological data sets over the far ocean during the period of June 2006 to December 2010 are used, including:

1. CALIPSO level $1 \mathrm{~b}$ data: CALIPSO is a polarizationsensitive lidar capable of measuring backscatter intensity at wavelengths of $532 \mathrm{~nm}$ and $1064 \mathrm{~nm}$. CALIOP level $1 \mathrm{~B}$ data (horizontal resolution of $333 \mathrm{~m}$ along the track) are calibrated and geolocated $532 \mathrm{~nm}$ and $1064 \mathrm{~nm}$ total attenuated backscatter and $532 \mathrm{~nm}$ perpendicular polarization components (Hostetler et al., 2006).

2. CloudSat 2B GEOPROF: Cloudsat carries a $94 \mathrm{GHZ}$ cloud profiling radar (CPR) with a horizontal resolution of $1.3 \mathrm{~km}$ cross track and $1.7 \mathrm{~km}$ along track. The 2B-GEOPROF product contains the cloud mask information that identifies where hydrometeors occur in individual profiles over the instrument noise floor (Mace, 2007).
3. ECMWF-AUX: contains temperature and pressure profiles from the European Centre for Medium-Range Weather Forecasts (ECMWF) operational analysis interpolated in time and space to the CloudSat track (Partain, 2004).

The cloud is identified by combining the CloudSat GEOPROF product and CALIPSO level 1B data (detailed in Wang et al., 2008 and Loknath et al., 2010). After cloud identification, clear-sky lidar profiles within a $25 \mathrm{~km}$ box were averaged to increase the signal-to-noise ratio (SNR). In this study, only clear-sky data within $50^{\circ} \mathrm{N}$ and $50^{\circ} \mathrm{S}$ and $200 \mathrm{~km}$ away from continents were used.

\subsection{BLH determination methodology with SONDE measurements}

The literature contains many methods for estimating BLH (see reviews in Seidel et al., 2010 for details). The main design of these methods is based on some common characteristics of ABL. Usually a capping inversion exists at the top of the ABL, which prevents the vertical transportation of heat, humidity and pollution. Below the capping inversion, usually the ABL is assumed to be well mixed. These different methods tried to identify ABL top characteristics to determine BLH with different variables such as temperature or humidity gradient, but often give different BLHs (Seidel et al., 2010). 


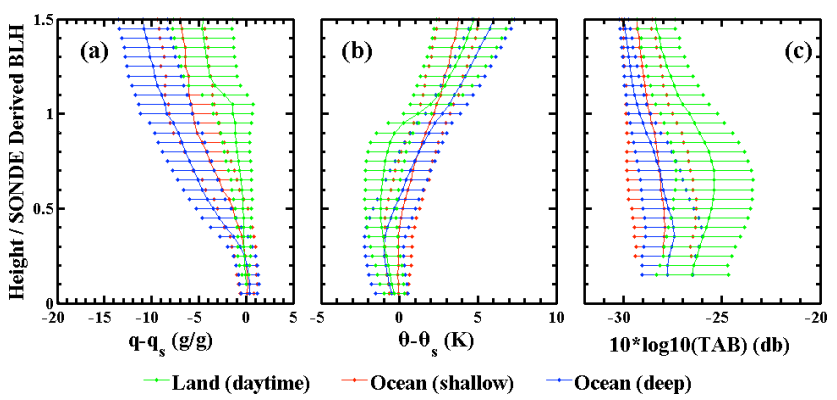

Fig. 2. Comparison of the ABL structure in terms of the mean and the standard deviation of the mixing ratio (a), potential temperature (b) and TAB (c) from $2 \mathrm{yr}$ (2007-2008) oceanic measurements and 3 yr (2007-2009) continental measurements. The height is normalized by the SONDE-derived BLH. The green and blue lines denote the cases with SONDE-derived BLH between $1.5 \mathrm{~km}$ and $2 \mathrm{~km}$ for land (498 observations) and ocean (deep cases, 1610 observations), respectively. The red line denotes the cases with SONDE-derived BLH between $0.8 \mathrm{~km}$ and $1.2 \mathrm{~km}$ for the ocean (shallow cases, 267 observations).

For SONDE, Seidel et al. (2010) recommended either the parcel method or the RI method to be the most reliable method under convective conditions, whereas the RI method was regarded as the most suitable method under conditions with mechanically produced turbulence. The parcel method determines the height of intersection of the actual potential temperature profile with the dry-adiabatic ascent starting at near-surface temperature (Holzworth, 1964, 1967, 1972). The RI method determines the BLH as the height at which $\mathrm{RI}$ is larger than the critical value $(=0.25)$, here, $\mathrm{RI}$ defined as (Vogelezang and Holtslag, 1996)

$$
\mathrm{RI}=\frac{g z(\theta(z)-\theta(s))}{\left.\theta(s)\left[(u(z)-u(s))^{2}+(v(z)-v(s))^{2}\right)\right]} .
$$

Good agreement was found for BLH derived by the parcel method and the RI method, whereas sometimes the parcel model is inapplicable, i.e., in the afternoon, due to the decrease in near-surface temperature (Hennemuth and Lammert, 2006). The RI method is suitable for both stable and convective boundary layers. This method relates the derived BLH to ABL processes - surface heating, wind shear and capping inversion, thus giving the BLH more physical meaning. The RI method is also not strongly dependent on sounding vertical resolution (Seidel et al., 2012). Therefore the RI method will be adopted in this study as the best estimation for lidar-based BLH evaluations.

\subsection{BLH detection methodology with ground-based lidar measurements}

For lidar observations, using different characteristics of returned backscatter to determine the BLH may give a different characteristic scale of ABL (Emeis et al., 2008). Five
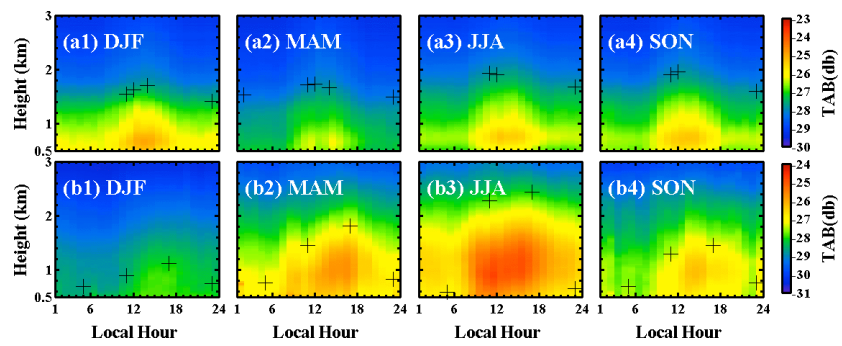

Fig. 3. Diurnal cycle of boundary layer aerosol structure at the marine site (2007-2008, top panel) and the continental site (20072009 , bottom panel). The black cross in each figure represents the BLH derived from SONDE with the RI number method.

methods were demonstrated in Fig. 1a-e, respectively. The threshold method (Fig. 1a) sets the BLH at the height of lidar aerosol signal above a certain threshold and will be detailed further in the next section. The gradient method (Fig. 1b), log-gradient method (Fig. 1c) and second derivation method (Fig. 1c) determine the BLH at the height corresponding to the minimum of the gradient, log-gradient and second derivation of lidar backscattering, respectively (Emeis et al., 2008). The variance method determines the BLH as the maximum of the variance profile (Emeis et al., 2008). As shown in Fig. 1a, the threshold method gives the highest BLH; the gradient and log-gradient method gives the second highest $\mathrm{BLH}$; and the second derivation and variance method gives the lowest BLH. Therefore a careful evaluation of their performance is needed. In this study, we would like to identify the BLH by lidar consistent with BLH from ABL thermodynamical structures. To achieve this goal, this paper will try to find suitable lidar-based methodology under different conditions to minimize the difference between lidar-derived BLH and traditionally SONDE-defined BLH.

Aerosol vertical distribution is strongly influenced by the ABL thermal structures, which are different over land and the ocean. Figure 2 shows the ABL structure varying with the normalized height in terms of the mean and the standard deviation of mixing ratio, potential temperature and TAB from $2 \mathrm{yr}$ (2007-2008) oceanic measurements and $3 \mathrm{yr}$ (2007-2009) continental measurements. Over land, a sharp gradient in the water vapor mixing ratio and potential temperature could be found near the ABL top. Below the capping inversion layer, a well-mixed layer could be found, with a nearly constant potential temperature and mixing ratio. The mixing layer height (MLH) could be treated as the BLH. The aerosol loading in the mixing layer is higher than the upper layer, which leads to a sharp gradient in TAB near the mixing layer top. However, the deep marine boundary layer (MBL) is more likely to be decoupled (Wood and Bretherton, 2004). As shown in Fig. 2, in deep MBL cases (BLH between $1.5 \mathrm{~km}$ and $2 \mathrm{~km}$ ), the mixing layer only occupies about $30 \%$ of the total ABL. The MLH is much shallower than the BLH and cannot be treated as BLH under this situation. A sharp 

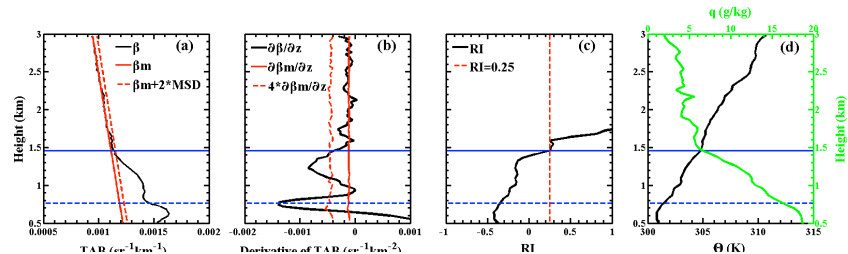

Fig. 4. Illustrations of the MPL, BLH and MLH identification methods for oceanic measurements (23:30 LT, 3 March 2007): (a) TAB; (b) TAB gradient; (c) RI; (d) potential temperature and mixing ratio. The blue solid line in each figure denotes the SONDE-derived BLH, and the blue dashed line denotes the MPL-derived MLH.

gradient near the mixing layer top could be found in humidity, temperature and TAB. In the shallow MBL cases (BLH between 0.8 and $1.2 \mathrm{~km}$ ), the ABL structure is quite similar to that over land, but not so well mixed. The gradients in humidity, temperature or TAB at the ABL top are not as sharp as those over land.

The diurnal boundary layer aerosol structures over different surfaces were further investigated. Figure 3 shows the averaged diurnal cycles of boundary layer aerosol structures over land and ocean in different seasons. The corresponding SONDE-derived diurnal cycle of BLHs were overlaid as a reference.

Over the oceans, the diurnal cycles of BLH are very weak in all seasons, because the daily cycle of the surface sensible heat flux is weak and often a persistent boundary layer with a capping inversion can be observed. There is more aerosol content below BLH, because the major source of marine aerosol is sea salt production by sea-spray processes at the sea surface. The sea salt aerosols will be vertically transported through turbulent mixing processes and be capped by inversion at the boundary layer top. The MBL shows decoupled structure when deeper. The lower layer near surface is well mixed and has much higher aerosol loading than the upper decoupled layer.

Over land, the boundary layer has a much stronger diurnal cycle, especially in MAM and JJA at the continental site, corresponding to the sensible heat flux variations at the surface. The aerosol layer structure over land is more complicated than that over the ocean, because aerosol here is not all locally produced. The aerosol layer over land is usually higher than BLH, mainly due to background aerosols or an elevated aerosol layer. Especially during night, when turbulence is weak, the residual layer still contains very high aerosol loadings and it is hard to find systematic characteristics to distinguish the boundary layer aerosol and the lofted aerosol. However, usually a sharp gradient of aerosol backscattering can be expected near the convective boundary layer top during daytime.

Therefore, considering their systematic different characteristics, different methodologies are needed for identifying BLH over ocean and land, as shown in Figs. 4 and 5.

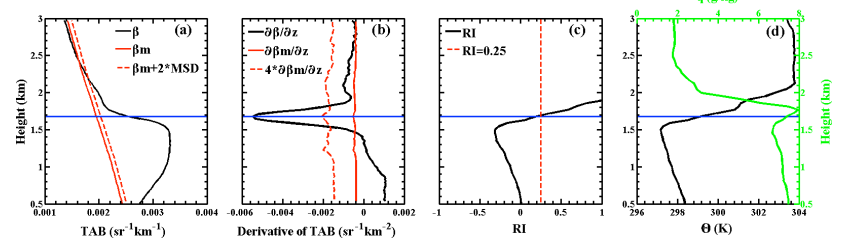

Fig. 5. Illustrations of MPL BLH identification methods for continental measurements during daytime (17:30 LT, 23 April 2007): (a) TAB; (b) TAB gradient; (c) RI; (d) potential temperature and mixing ratio. The blue line in each figure denotes the SONDE-derived BLH.

Over the ocean, the threshold method could be used to determine the BLH. BLH is defined at the point where $\mathrm{TAB}>\beta_{\text {thr }}^{\prime}$; here $\beta_{\text {thr }}^{\prime}$ is defined as

$\beta_{\mathrm{thr}}^{\prime}=\beta_{\mathrm{m}}^{\prime}+2 \mathrm{MBV}$,

where $\beta_{\mathrm{m}}^{\prime}$ is the attenuated molecular backscattering, estimated based on temperature and pressure profiles from SONDE data or from other sources; MBV is the measured backscatter variation, estimated as the standard deviation of measured attenuated backscatter coefficients within 5 to $7 \mathrm{~km}$.

BLH is searched from top down as the first three points larger than $\beta_{\mathrm{thr}}^{\prime}$. To remove the possible elevated layer, we keep searching the strong peak near the BLH. If there exists a strong peak near formerly identified BLH, the profile will be identified as the elevated layer case and the layer base (where the gradient changes its sign) is identified and treated as BLH.

Over land, the gradient method could be used to determine the BLH (or MLH) at daytime, by determining the first minimum peak of the TAB gradient smaller than the threshold $\left(=4 \times d \beta_{\mathrm{m}}^{\prime} ; d \beta_{\mathrm{m}}^{\prime}\right.$ is the gradient of molecular backscattering) from bottom upward. The gradient method could be used to determine the marine MLH, as the dashed blue line in Fig. 4.

\subsection{Methodology for space-borne lidar}

BLH can be determined with collocated CALIPSO level 1B data by an improved threshold method due to its lower signalto-noise ratio. For molecular attenuation corrected signals, the threshold $\beta_{\mathrm{thr}}^{\prime}$ is still chosen as

$\beta_{\mathrm{thr}}^{\prime}=\beta_{\mathrm{m}}^{\prime}+2 \times \mathrm{MBV}$.

Here, $\beta_{\mathrm{m}}^{\prime}$ is the molecular backscattering, estimated by temperature and pressure profiles from ECMWF-AUX products; MBV is the measured backscatter variation, estimated as the standard deviation of measured attenuated backscatter coefficients from 30 to $40 \mathrm{~km}$.

Considering the poor SNR in $532 \mathrm{~nm}$ channels, $532 \mathrm{~nm}$ $\left(\beta_{532}^{\prime}\right)$ and $1064 \mathrm{~nm}\left(\beta_{1064}^{\prime}\right)$ attenuated backscatter were combined to determine the aerosol layer, because $\beta_{1064}^{\prime}$ is less 
noised and molecular attenuated. For each aerosol layer detected by the threshold method, it should exist in both the channels.

The detailed aerosol layer identification scheme is as follows:

1. For each height, compute molecular backscattering coefficients $\beta_{\mathrm{m}}^{\prime}$, two-way transmittances $T_{\mathrm{m}}^{2}$ and MBV at $532 \mathrm{~nm}$ and $1064 \mathrm{~nm}$; and then the corrections for molecular attenuations were applied to signals, as

$\beta^{\prime}=\beta_{\mathrm{obs}}^{\prime} / T_{\mathrm{m}}^{2}$.

Here, $\beta_{\text {obs }}^{\prime}$ is the measured signal; $\beta^{\prime}$ is the corrected signal.

2. Build up aerosol masks at each channel. To compensate for the attenuation incurred within and below the aerosol layers, the estimated aerosol backscattering coefficients $\beta_{\mathrm{e}}$ were used to identify layers. The $\beta_{\mathrm{e}}$ were computed with the forward method (Klett, 1981; Fernald, 1983; Young and Vaughan, 2009) by assuming a layer top at $8 \mathrm{~km}$. Lidar ratios $(S)$ were chosen as $25(532 \mathrm{~nm})$ and $40(1064 \mathrm{~nm})$ (Vaughan et al., 2009). While retrieving at a certain level, $\beta_{\mathrm{e}}$ will be set to zero if $\beta_{\mathrm{e}}+\beta_{\mathrm{m}}$ is smaller than $\left(\beta_{\mathrm{m}}^{\prime}+2 \mathrm{MBV}\right) / T_{\mathrm{e}}^{2}$ (here, $T_{\mathrm{e}}^{2}$ is the estimated transmittances of aerosols with $\beta_{\mathrm{e}}$ ). Then, the aerosol mask will be set to 1 for each height bin where $\beta_{\mathrm{e}}>0$.

3. Refine the aerosol mask by combining $532 \mathrm{~nm}$ and $1064 \mathrm{~nm}$ aerosol mask profiles. First, for each wavelength, we remove the aerosol layer with less than 3 points. Then we combine 532 and $1064 \mathrm{~nm}$ aerosol mask profiles and set the new aerosol mask to be 1 if the mask in any of the profiles equals 1 at a certain height. Finally, to get a more accurate aerosol layer top, a 3-range bin moving smooth is applied to $\beta_{532}^{\prime}$ profiles, and then the aerosol layer top is defined as the highest point extending from the certain aerosol layer where $\beta_{532}^{\prime}$ is larger than $\beta_{\text {thr }}^{\prime}$ in Eq. (1) and the color ratio $(1064 \mathrm{~nm} / 532 \mathrm{~nm})$ is larger than 0.06 .

4. Final check with elevated layer. In most of the cases, a multi-layer aerosol structure can be identified with gaps between layers in an aerosol extinction profile. When a multi-layer aerosol case is identified, only the lowest layer is regarded as the boundary layer aerosol. Although this approach can remove most elevated layers, there are still a few cases of the elevated layer connected with the boundary layer aerosol. Therefore, additional tests are needed. If the initial identified BLH is higher than $2.5 \mathrm{~km}$ and the extinction profile has a strong peak closed to the initially identified BLH, the elevated layer exists. Then, the elevated layer base (where the gradient of extinction changes its sign) is used as the BLH.

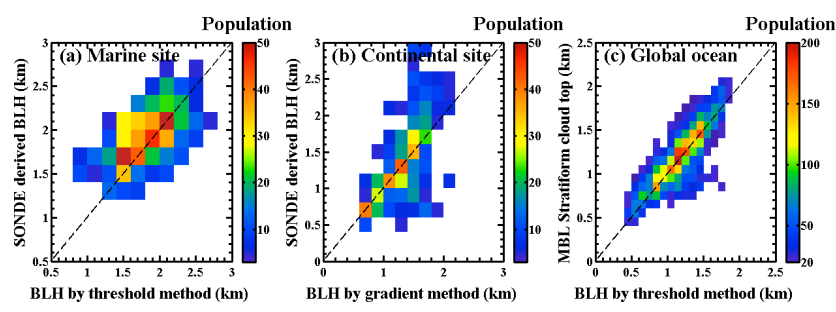

Fig. 6. Comparison of BLHs between SONDE derived and MPL derived (a) with the threshold method at the marine site and (b) with the gradient method at the continental site; comparison between marine BLH derived with the threshold method and marine boundary layer stratiform cloud top over the global ocean from CALIPSO measurements (c).

5. Identify the MLH by the gradient method. The gradient of $\beta_{\mathrm{e}}$ is calculated after three points moving smoothing. Then the MLH is determined from bottom up as the first point with $\beta_{\mathrm{e}}$ gradient larger than 4 times the molecular backscattering gradient.

\section{Results and discussion}

\subsection{Validation}

The lidar-based algorithms discussed above are applied to MPL observations at the marine site (2007-2008, daytime and nighttime, 10194 profiles) and the continental site (2007-2009, daytime only, 5438 profiles). 3-hour averaged BLH were collocated with SONDE observations for comparison, as shown in Fig. 6a and b. MPL-derived BLHs show good agreement with SONDE-determined BLHs. Over the ocean, the bias and mean square error (MSE) of MPLderived BLH is $-0.12 \pm 0.24 \mathrm{~km}$, and $83 \%$ of points have a percentage difference of less than $30 \%$. Over land, the bias and MSE is $-0.04 \pm 0.27 \mathrm{~km} .74 \%$ of points have a percentage difference of less than $30 \%$. Over land (Fig. 6b), unidentified elevated aerosol layers result in a few points with MPLderived BLH much higher than SONDE-derived BLH. Under strong convection situation over land, the gradient method often underestimates BLH according to SONDE results, but the threshold method performs better under this situation. Therefore, no single approach can cover all situations over land.

The diurnal and seasonal cycles of BLH from $1 \mathrm{~h}$-averaged MPL observations show good agreement with those from SONDE, especially over the ocean (Fig. 7). Over land, the MPL-derived BLH accords well in warm seasons but shows a positive bias $(+0.3 \mathrm{~km})$ in cold seasons. The positive bias in the cold season is due to the overlap corrections. Especially at continental places under stable conditions in wintertime almost no convective ABL development can be expected. Possibly very shallow ABL are not "seen" and thus lofted layer tops are detected as BLH, which are higher than the SONDE-derived BLH. This suggests that lidar-based 

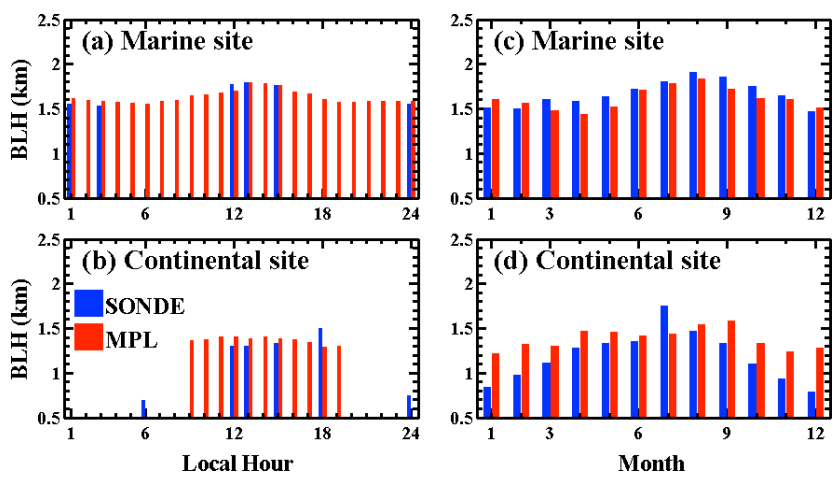

Fig. 7. Diurnal cycles of BLH at the marine site (a) and the continental site (b); and annual cycles of BLH at the marine site (c) and the continental site (d).

BLH identification over land could be further improved. During night, aerosol structure is less correlated with boundary layer thermodynamical structure, especially under cold surface temperature. Another issue is the overlap issues, which is similar to that in the cold season over land, because the nighttime BLH is often near to or is lower than $500 \mathrm{~m}$.

The lidar-based algorithms were then applied to CALIPSO observations over the global ocean to derived $4 \mathrm{yr}$ global ocean BLH data sets. Marine stratiform clouds were a good proxy to estimate marine BLH from satellite-retrieved cloudtop heights in previous studies (Minnis et al., 1992; Wood and Bretherton 2004; Ahlgrimm and Randall, 2006; Zuidema et al., 2009; Karlsson et al., 2010). Therefore, marine stratiform cloud top height was used to evaluate the large database in this study. Cloud top height and cloud type was provided by Cloudsat 2B-CLD-CLASS-LIDAR data (Wang, 2011). Stratiform cloud height was collocated and averaged into the same $25 \mathrm{~km}$ grid box as described in Sect. 2.4. Data with partially cloudy condition (with cloud fraction between 0.1 and 0.7 ) in a $25 \mathrm{~km}$ grid box were used to evaluate the global BLH. With partially cloudy cases, we could determine both BLH and cloud top within the grid. Larger than 0.1 cloud fractions make sure to have at least 2 cloudy profiles for cloud top calculations. Cases with cloud fraction larger than 0.7 were not included in the evaluation because there are not enough cloud-free CALIPSO profiles within the $25 \mathrm{~km}$ grid box to be averaged to achieve the needed signal-to-noise ratio. As shown in Fig. 6c, CALIPSO-derived BLH shows good agreement with marine stratiform cloud height. The bias and MSE of CALIPSO-derived BLH is $-0.08 \pm 0.37 \mathrm{~km}$. $75 \%$ of points have a percentage difference of less than $30 \%$.

\subsection{Discussion}

Over the ocean, former studies showed that the cloud-topped MLH is shallower than BLH when deepening, and that the ABL is not well mixed above the MLH (Wood and Bretherton, 2004). Bretherton and Wyant (1997) showed that the decoupling structure under cloudy conditions is mainly driven by an increasing ratio of the surface latent heat flux to the net radiative cooling in the cloud. Other factors, such as drizzle, the vertical distribution of radiative cooling in the cloud, and sensible heat fluxes, play less important roles. However, early observations are mainly limited to specific case studies (Wood and Bretherton, 2004). The decoupling mechanisms of MBL are still not well understood, especially for no cloud-topped MBL. Lidar can provide MLH and BLH simultaneously to further study the decoupling.

Figure $8 \mathrm{a}, \mathrm{b}$ and $\mathrm{c}$ show the MBL structure in terms of water vapor, temperature, and aerosol TAB as a function of $\mathrm{BLH}$ determined from ground-based SONDE measurements during 2007-2008 at the marine site. Figure $8 \mathrm{a}$ and $\mathrm{b}$ show that the MPL-derived MLH is coincident with sharp gradients of temperature and humidity. The mixing layer is moister and more unstable than the ABL above the MLH (decoupled from the near-surface mixing layer). The decoupling becomes clear when BLH is deeper than $1 \mathrm{~km}$. Figure $8 \mathrm{c}$ shows the aerosol structure changing with SONDE determined BLH systematically. The aerosol intensity gradients at the MLHs are consistent with temperature and water vapor jumps. Therefore the gradient method is reliable to identify the marine MLH. To further illustrate this point, CALIPSO observations within a $10^{\circ}$ latitude $\times 20^{\circ}$ longitude box centered at the marine site are shown in Fig. $8 \mathrm{~d}$ and e. It is clear that marine $\mathrm{ABL}$ aerosols show distinct signatures for the BLH and MLH. Figure 8d shows more aerosol contents in the mixing layer than the rest of $\mathrm{ABL}$ in terms of lidar signal intensities. Combined with two wavelength CALIPSO measurements, Fig. 8e provides the color ratio $(1064 \mathrm{~nm} / 532 \mathrm{~nm})$ of aerosols. The larger the color ratio is, the larger the aerosol particle size is. Thus, Fig. 8e shows that the mixing layer has a relatively larger particle size than the rest of the ABL, which is consistent with the higher water vapor mixing ratio in the mixing layer. These results showed that the decoupling occurs frequently under cloud-free conditions. A similar structure could be found over the global ocean. The mean occurrence of decoupling as observed at the marine site is $67.8 \%$, and that as observed by CALIPSO over the global ocean is $56.8 \%$. With the global marine BLH and MLH data sets from CALIPSO measurements, factors controlling MBL decouple structure over the global ocean will be further studied in the future.

\section{Conclusions}

In this study, lidar-based methods are developed to provide consistent BLH and MLH determinations as those based on the thermodynamical properties. The results are evaluated with multi-year data. A global lidar-based MBL structure database was created.

With ACRF MPL and radiosonde measurements, diurnal cycles of boundary layer aerosol structures over land and 

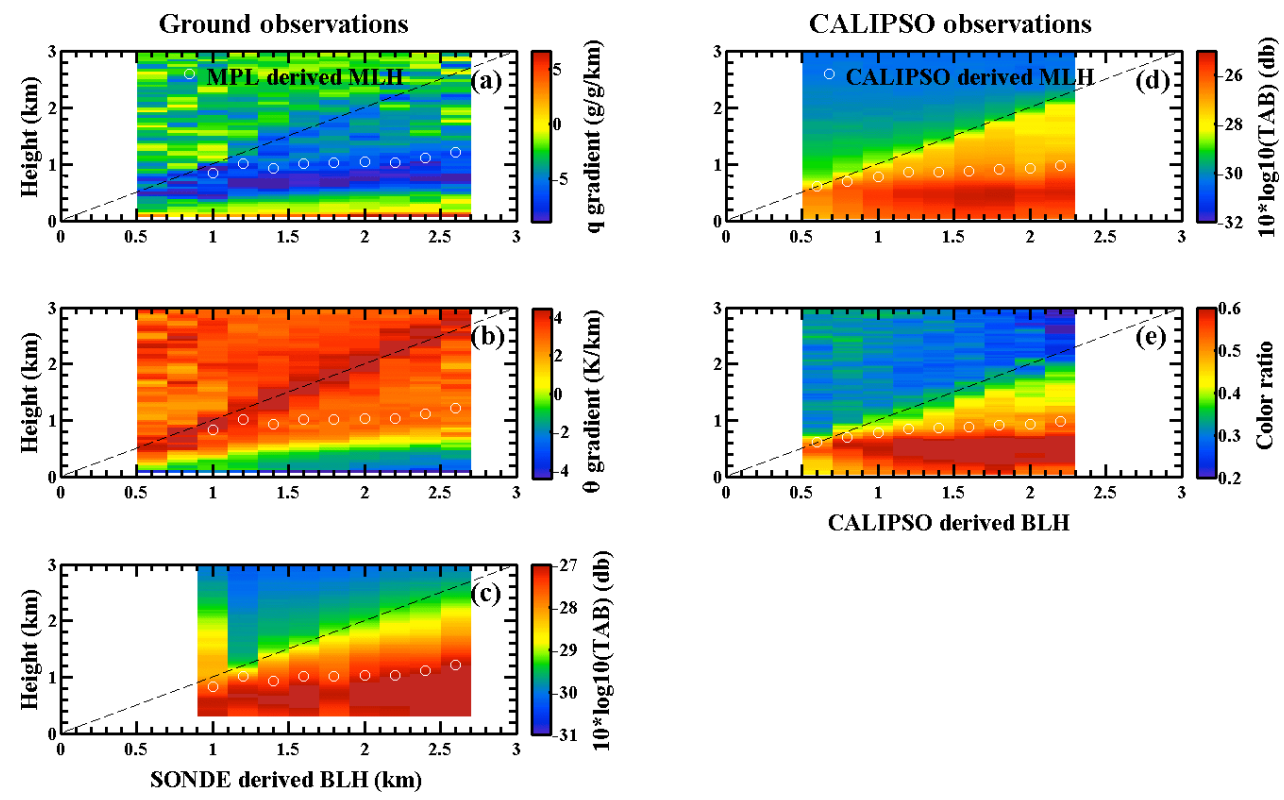

Fig. 8. Left panel: Ground-based observations at the marine site of marine boundary layer decoupled structure in terms of mixing ratio (a), potential temperature (b) and TAB (c). Right: The same but for satellite-based observations near the marine site in terms of TAB (d) and color ratio $(1024 \mathrm{~nm} / 532 \mathrm{~nm})(\mathbf{e})$. The white circles are the MPL-derived MLH (a, b, c) or CALIPSO-derived MLH (d, e).

the ocean are investigated and compared. The results showed systematically different characteristics requiring different approaches for land and ocean to determine the BLH and MLH with lidar aerosol measurements. Over the ocean, the MBL shows a decoupled structure. The aerosol layer top shows good according with BLH and could be easily identified by the threshold method, and the MLH could be identified by gradient methods. Over land, the boundary layer aerosol structure can be very complicated due to several reasons, such as that the turbulence in the nocturnal boundary layer is very weak and the residual layer still has very high aerosol loading, or that the aerosol over land is not predominantly locally produced, thus there are elevated aerosol layers transported from non-local sources. The aerosol layer top is usually higher than BLH. The daytime BLH could be identified by the gradient method using lidar observations.

Comparison between MPL-derived BLH and SONDEderived BLH shows good agreement. Over the ocean, the bias and MSE of MPL-derived BLH is $-0.12 \pm 0.24 \mathrm{~km}$ and $83 \%$ of points have a relative error smaller than $30 \%$. Over land, the bias of MPL-derived BLH is $-0.04 \pm 0.27 \mathrm{~km}$ and $74 \%$ of points have a relative error smaller than $30 \%$. However, the BLH identification over land still needs further improvements, especially during nighttime. During night, aerosol structure is less correlated with boundary layer thermodynamical structure. This is a general weakness of using lidar aerosol measurements for BLH determination. It will be our future work to further improve the BLH identification over land.
The improved lidar-based method was further applied to CALIPSO cloud-free observations, and a global marine BLH and MLH database was developed. The BLHs were further evaluated with global marine stratiform cloud top. The mean bias and MSE of CALIPSO-derived BLH is $-0.08 \pm 0.37 \mathrm{~km}$ and $75 \%$ of points have a relative error smaller than $30 \%$. This indicates that CALIPSO aerosol measurements offer reliable BLH over oceans with our method. The gradient method applied to CALIPSO aerosol measurements could provide reliable MLHs, which corresponds well with MBL potential temperature and water vapor structure. The global marine ABL structure database developed in this study is useful for model evaluations and for process study to improve the ABL simulations in the weather, climate, and air quality models. The results show that MBL are often decoupled under cloud free conditions. With the data set, we will further understand the MBL decoupling structure and related mechanisms.

Acknowledgements. This research was funded by NASA grant NNX10AN18G, and partially supported by DOE DE-SC0006974 as part of the ASR program. Tao Luo's effort was supported by the National Natural Science Foundation of China (41105018). The authors acknowledge the US Department of Energy ARM Climate Research Facility. The authors acknowledge the editors' and referees' efforts in improving the manuscript.

Edited by: U. Friess 


\section{References}

Ahlgrimm, M. and Randall, D. A.: Diagnosing Monthly Mean Boundary Layer Properties from Reanalysis Data using a Bulk Boundary Layer Model, J. Atmos. Sci., 63, 998-1012, doi:10.1029/2012JD017598, 2006.

Ao, C. O., Waliser, D. E., Chan, S. K., Li, J.-L., Tian, B., Xie, F., and Mannucci, A. J.: Planetary boundary layer heights from GPS radio occultation refractivity and humidity profiles, J. Geophys. Res., 117, D16117, doi:10.1029/2012JD017598, 2012.

Baars, H., Ansmann, A., Engelmann, R., and Althausen, D.: Continuous Monitoring of the Boundary-layer Top with Lidar. Atmos. Chem. Phys., 8, 7281-7296, doi:10.5194/acp-8-7281-2008, 2008.

Boers, R. and Eloranta, E. W.: Lidar Measurements of the Atmospheric Entrainment Zone and Potential Temperature Jump across the Top of the Mixed Layer, Bound.-Lay. Meteorol., 34, 357-375, 1986.

Boers, R., Eloranta, E. W., and Coulter, R. L.: Lidar Observations of Mixed Layer Dynamics: Tests of Parametrized EntrainmentModels of Mixed Layer Growth Rate, J. Clim. Appl. Meteorol., 23, 247-266, 1984.

Bretherton, C. S. and Wyant, M. C.: Moisture transport, Lowertropospheric Stability, and Decoupling of Cloud-topped Boundary Layers, J. Atmos. Sci., 54, 148-167, 1997.

Coulter, R.: Micropulse Lidar (MPL) Handbook, DOE/SCARM/TR-019, available at: http://www.arm.gov/publications/ tech_reports/handbooks/mpl_handbook.pdf?id=32 (last access: 21 November 2013), 2012.

Emeis, S., Schafer, K., and Munkel, C.: Surface-based Remote Sensing of the Mixing-layer Height - a Review, Meteorol. Z., 17, 621-630, 2008.

Erickson Ill, D. J., Oglesby, R. J., Elliott, S., Steffen, W., and Brasseur, G.: Challenges in Earth System Modeling: Approaches and Applications, US Department of Energy Publications, Paper 64, available at: http://digitalcommons.unl.edu/usdoepub/64 (last access: 29 August 2013), 2008.

Fernald, R. G.: Analysis of atmospheric lidar observations some comments, Appl. Optics, 23, 652-653, 1983.

Ferrare, R., Clayton, M., Turner, D., Newsom, R., and Scarino, A.: Raman Lidar Retrievals of Mixed-layer Heights over the TWP Darwin and SGP Sites, 4th Atmospheric System Research (ASR) Science Team Meeting, Potomac, Maryland, 2013.

Flamant, C., Pelon, J., Flamant, P. H., and Durand, P.: Lidar Determination of the Entrainment Zone Thickness at the Top of the Unstable Marine Atmospheric Boundary Layer, Bound.-Lay. Meteorol., 83, 247-284, 1997.

Garratt, J. R.: The Atmospheric Boundary Layer, Cambridge Univ. Press, Cambridge, UK, 335 pp., 1992.

Guo, P., Kuo, Y.-H., Sokolovskiy, S. V., and Lenschow, D. H.: Estimating Atmospheric Boundary Layer Depth using COSMIC Radio Occultation Data, J. Atmos. Sci., 68, 1703-1713, 2011.

Haeffelin, M., Angelini, F., Morille, Y., Martucci, G., Frey, S., Gobbi, G. P., Lolli, S., O’Dowd, C. D., Sauvage, L., XuerefRémy, I., Wastine, B., and Feist, D. G.: Evaluation of MixingHeight Retrievals from Automatic Profiling Lidars and Ceilometers in View of Future Integrated Networks in Europe, Bound.Lay. Meteorol., 143, 49-75, 2012.

Hannay, C., Williamson, D. L., Hack, J. J., Kiehl, J. T., Olson, J. G., Klein, S. A., Bretherton, C. S., and Köhler, M.: Evalua- tion of Forecasted Southeast Pacific Stratocumulus in the NCAR, GFDL, and ECMWF models, J. Climate, 22, 2871-2889, 2009.

Hennemuth, B. and Lammert, A.: Determination of the Atmospheric Boundary Layer Height from Radiosonde and Lidar Backscatter, Bound.-Lay. Meteorol., 120, 181-200, 2006.

Holzworth, G. C.: Estimates of Mean Maximum Mixing Depths in the Contiguous United States, Mon. Weather Rev., 92, 235-242, 1964.

Holzworth, G. C.: Mixing depths, Wind speeds and Air pollution Potential for Selected Locations in the United States, J. Appl. Meteorol., 6, 1039-1044, 1967.

Holzworth, G. C.: Mixing depths, Wind speeds, and Potential for Urban Pollution throughout the Contiguous United States, EPA, Office of Air Programs Publ, Research Triangle Park, NC, AP101, 118 pp., 1972.

Hooper, W. P. and Eloranta, E. W.: Lidar Measurements of Wind in the Planetary Boundary Layer: the Method, Accuracy and Results from Joint Measurements with Radiosonde and Kytoon, J. Clim. Appl. Meteorol., 25, 990-1001, 1986.

Hostetler, C., Liu, Z., Reagan, J., Vaughan, M., Osborn, M., Hunt, W. H., Powell, K. A., and Trepte, C.: CALIOP Algorithm Theoretical Basis Document - Part 1: Calibration and Level 1 Data Products, PC-SCI-201, Release 1.0, NASA Langley Research Center, Hamp10 ton, VA, 2006.

Jordan, N. S., Hoff, R. M., and Bacmeister, J. T.: Validation of Goddard Earth Observing System-version 5 MERRA Planetary Boundary Layer Heights using CALIPSO, J. Geophys. Res., 115, D24218, doi:10.1029/2009JD013777, 2010.

Karlsson, J., Svensson, G., Cardoso, S., Teixeira, J., and Paradise, S.: Subtropical Cloud-Regime Transitions: Boundary Layer Depth and Cloud-Top Height Evolution in Models and Observations, J. Appl. Meteorol. Clim., 49, 1845-1858, 2010.

Klett, J.: Stable analytical inversion solution for processing lidar returns, Appl. Optics, 20, 211-220, doi:10.1364/AO.20.000211, 1981.

Kukkonen, J., Olsson, T., Schultz, D. M., Baklanov, A., Klein, T., Miranda, A. I., Monteiro, A., Hirtl, M., Tarvainen, V., Boy, M., Peuch, V.-H., Poupkou, A., Kioutsioukis, I., Finardi, S., Sofiev, M., Sokhi, R., Lehtinen, K. E. J., Karatzas, K., San José, R., Astitha, M., Kallos, G., Schaap, M., Reimer, E., Jakobs, H., and Eben, K.: A review of operational, regional-scale, chemical weather forecasting models in Europe, Atmos. Chem. Phys., 12, 1-87, doi:10.5194/acp-12-1-2012, 2012.

Lammert, A. and Bösenberg, J.: Determination of the Convective Boundary Layer Height with Laser Remote Sensing, Bound.Lay. Meteorol., 119, 159-170, 2006.

Lenderink, G. and Holtslag, A. A. M.: Evaluation of Kinetic Energy Approach for Modeling Turbulent Fluxes in Stratocumulus, Mon. Weather Rev., 128, 244-258, 2000.

Liu, S. and Liang, X.-Z.: Observed Diurnal Cycle Climatology of Planetary Boundary Layer Height, J. Climate, 22, 5790-5809, 2010.

Loknath A., Wang, Z., and Liu, D.: Microphysical Properties of Antarctic Polar Stratospheric Clouds and their Dependence on Tropospheric Cloud Systems, J. Geophys. Res., 15, D00H18, doi:10.1029/2009JD012125, 2010.

Mace G.: Level 2 GEOPROF Product Process Description and Interface Control Document Algorithm version 5.3, available at: http://www.cloudsat.cira.colostate.edu/ICD/2B-GEOPROF/ 
2B-GEOPROF_PDICD_3.0.pdf (last access: 29 August 2013), 2007.

Martucci, G., Matthey, R., Mitev, V., and Richner, H.: Comparison between Backscatter Lidar and Radiosonde Measurements of the Diurnal and Nocturnal Stratification in the Lower Troposphere, J. Atmos. Ocean. Technol., 24, 1231-1244, 2007.

Mather, J. H. and Voyles, J. W.: The Arm Climate Research Facility: A Review of Structure and Capabilities, Bull. Amer. Meteor. Soc., 94, 377-392, 2013.

McGrath-Spangler, E. L. and Denning, A. S.: Estimates of North American Summertime Planetary Boundary Layer Depths Derived from Space-borne Lidar, J. Geophys. Res., 117, D15101, doi:10.1029/2012JD017615, 2012.

McGrath-Spangler, E. L. and Denning, A. S.: Global Seasonal Variations of Midday Planetary Boundary Layer Depth from CALIPSO Space-borne LIDAR, J. Geophys. Res. Atmos., 118, 1226-1233, 2013.

Melfi, S. H., Sphinhirne, J. D., Chou, S. H., and Palm, S. P.: Lidar Observations of the Vertically Organized Convection in the Planetary Boundary Layer over the Ocean, J. Climate Appl. Meteorol., 24, 806-821, 1985.

Menut, L., Flamant, C., Pelon, J., and Flamant, P. H.: Urban Boundary-layer Height Determination from Lidar Measurements over the Paris Area, Appl. Optics, 38, 945-954, 1999.

Minnis, P., Heck, P. W., Young, D. F., Fairall, C. W., and Snider, J. B.: Stratocumulus Cloud Properties Derived from Simultaneous Satellite and Island-based Instrumentation during FIRE, J. Appl. Meteorol., 31, 317-339, 1992.

Partain, P.: Cloudsat ECMWF-AUX Auxiliary Data Process Description and Interface Control Document, available at: http://www.cloudsat.cira.colostate.edu/ICD/ECMWF-AUX/ ECMWF-AUX_PDICD_3.0.pdf (last access: 29 August 2013), 2004.

Ratnam, M. V. and Basha, S. G.: A Robust Method to Determine Global Distribution of Atmospheric Boundary Layer Top from COSMIC GPS RO Measurements, Atmos. Sci. Lett., 11, 216222,2010 .

Seibert, P., Beyrich, F., Gryning, S.-E., Joffre, S., Rasmussen, A., and Tercier, P.: Review and Intercomparison of Operational Methods for the Determination of the Mixing Height, Atmos. Environ., 34, 1001-1027, 2000.

Seidel, D. J., Ao, C. O., and Li, K.: Estimating Climatological Planetary Boundary Layer Heights from Radiosonde Observations: Comparison of Methods and Uncertainty Analysis, J. Geophys. Res., 115, D16113, doi:10.1029/2009JD013680, 2010.

Seidel, D. J., Zhang, Y., Beljaars, A., Golaz, J.-C., Jacobson, A. R., and Medeiros, B.: Climatology of the Planetary Boundary Layer over the Continental United States and Europe, J. Geophys. Res., 117, D17106, doi:10.1029/2012JD018143, 2012.

Sicard, M., Peèrez, C., Rocadenbosch, F., Baldasano, J. M., and Garciìa-Vizcaino, D.: Mixed-layer Depth Determination in the Barcelona Coastal Area from Regular Lidar Measurements: Methods, Results and Limitations, Bound.-Lay. Meteorol., 119, 135-157, 2006.

Stevens, B.: Entrainment in Stratocumulus Topped Mixed Layers, Q. J. Roy. Meteorol. Soc., 128, 2663-2689, 2002.

Stull, R. B.: An Introduction to Boundary Layer Meteorology, Kluwer Academic Publishers, Norwell, MA, 1988.
Stull, R. B. and Eloranta, E. W.: Boundary Layer Experiment 1983 , Bull. Amer. Meteorol. Soc., 65, 450-456, 1984.

Tombrou, M., Dandou, A., Helmis, C., Akylas, E., Angelopoulos, G., Flocas, H., Assimakopoulos, V., and Soulakellis, N.: Model Evaluation of the Atmospheric Boudary Layer and Mixed-layer Evolution, Bound.-Lay. Meteorol., 124, 61-79, 2007.

Vaughan M. A., Powell, K. A., Kuehn, R., Hostetler, C. A., Kuehn, R. E., Hunt, W. H., Getzewich, B. J., Young, S. A., Liu, Z., and McGill, M. J.: Fully Automated Detection of Cloud and Aerosol Layers in the CALIPSO Lidar Measurements, J. Atmos. Ocean. Technol., 25, 2034-2050, 2009.

Vogelzang, D. H. P. and Holtslag, A. A. M.: Evaluation and Model Impacts of Alternative Boundary-Layer Height Formulations, Bound.-Lay. Meteorol., 81, 245-269, 1996.

Wang, Z.: 2B-CLDCLASS-LIDAR Interface Control Document, available at: http://www.cloudsat.cira.colostate.edu/icd pdf.php?avid=_36\&pvids=_12 (last access: 29 August 2013), 2011.

Wang, Z. and Sassen, K.: Cloud Type and Macrophysical Property Retrieval Using Multiple Remote Sensors, J. Appl. Meteorol., 40, 1665-1682, 2001.

Wang, Z., Stephens, G., and Deshler, T.: Association of Antarctic polar stratospheric cloud formation on tropospheric cloud systems, Geophys. Res. Lett., 35, L13806, doi:10.1029/2008GL034209, 2008.

Wood, R. and Bretherton, C. S.: Boundary Layer Depth, Entrainment, and Decoupling in the Cloud-Capped Subtropical and Tropical Marine Boundary Layer, J. Climate, 17, 3576-3588, 2004.

Wyant, M. C., Wood, R., Bretherton, C. S., Mechoso, C. R., Bacmeister, J., Balmaseda, M. A., Barrett, B., Codron, F., Earnshaw, P., Fast, J., Hannay, C., Kaiser, J. W., Kitagawa, H., Klein, S. A., Köhler, M., Manganello, J., Pan, H.-L., Sun, F., Wang, S., and Wang, Y.: The PreVOCA experiment: modeling the lower troposphere in the Southeast Pacific, Atmos. Chem. Phys., 10, 4757-4774, doi:10.5194/acp-10-4757-2010, 2010.

Xie, F., Wu, D. L., Ao, C. O., Mannucci, A. J., and Kursinski, E. R.: Advances and limitations of atmospheric boundary layer observations with GPS occultation over southeast Pacific Ocean, Atmos. Chem. Phys., 12, 903-918, doi:10.5194/acp-12-903-2012, 2012.

Xie, S., McCoy, R. B., Klein, S. A., Cederwall, R. T. , Wiscombe, W. J., Jensen, M. P., Johnson, K. L., Clothiaux, E. E., Gaustad, K. L., Long, C. N., Mather, J. H. , McFarlane, S. A., Shi, Y., Golaz, J.-C. , Lin, Y., Hall, S. D., McCord, R. A., Palanisamy, G., and Turner, D. D.: Clouds and More: ARM Climate Modeling Best Estimate Data, Bull. Amer. Meteor. Soc., 91, 13-20, 2010.

Young, S. A. and Vaughan, M. A.: The Retrieval of Profiles of Particulate Extinction from Cloud-Aerosol Lidar Infrared Pathfinder Satellite Observations (CALIPSO) Data: Algorithm Description, J. Atmos. Oceanic Technol., 26, 1105-1119, 2009.

Zilitinkevich, S. S.: The Height of the Atmospheric Planetary Boundary layer: State of the Art and New Development. National Security and Human Health Implications of Climate Change, Springer Netherlands, 147-161, 2012.

Zuidema, P., Painemal, D., Szoeke, S. de, and Fairall, C.: Stratocumulus Cloud-Top Height Estimates and Their Climatic Implications, J. Climate, 22, 4652-4666, 2009. 